\title{
LA EFICIENCIA DE LOS MEDIOS ALTERNATIVOS O ADECUADOS DE RESOLUCIÓN DE CONFLICTOS FRENTE AL SISTEMA PROCESAL CIVIL
}

\author{
FRANCISKOVIC INGUNZA, Beatriz * \\ TORRES ANGUlo, Carlos *
}

SUMARIO: 1 Generalidades sobre las formas de solución de todo conflicto. -2 . Autotutela. - 3. El proceso. - 4. El principio de contradicción. - 5. Tipologías utilizadas. -6 . Conclusiones.

\section{Generalidades sobre las formas de solución de todo conflicto}

Don Francisco Ramos Méndez empieza su extraordinaria obra El Sistema procesal español señalando que: "Todo el sistema procesal, el punto central y el punto de partida de él debe tener a la persona como eje ${ }^{, 250}$. Idea que, como una especie de ideario o una declaración de principios nos parece fundamental para empezar el tratamiento de cualquier sistema de resolución de conflictos que se pretenda establecer. Todo sistema procesal o de resolución de conflictos debe tener como punto central de partida al ser humano.

Previamente al tratamiento de los medios o mecanismos alternativos de resolución de conflictos, se ha presentado una discusión teórica propuesta más por los especialistas en Gestión de Conflictos que por los procesalistas, respecto a si los medios de resolución de conflictos corresponden a un sistema procesal o de este último sólo es parte el proceso. Nos dice Gozaíni, insigne procesalista argentino, que "La simple resolución del problema no habilita a considerarlos como equivalentes jurisdiccionales o sustitutivos de la función jurisdiccional o mecanismos supletorios del proceso común, sencillamente, porque el método actuado no es un proceso, el tercero que actúa no tiene jurisdicción y la entrada a estos sistemas alternativos es una cuestión que puede afectar el acceso a la justicia"251, por ello propugna el surgimiento de una nueva disciplina que puede denominarse Gestión de Conflictos, Administración de Conflictos o Formas Alternativas para la resolución de controversias, dejando reservado al Derecho procesal una etapa ulterior de revisión a fin de dilucidar su conformidad al debido proceso.

* Abogada. Conciliadora y Árbitro adscrita a varias instituciones. Docente de la Universidad San Martín de Porres, Científica del Sur y Ricardo Palma. Socia y Sub Gerente de Franciskovic Asociados. Discente de Maestría de Derecho Procesal Civil en la PUCP y Egresada de la maestría en Derecho Civil en la USMP.

** Licenciado en Derecho por la Pontificia Universidad Católica del Perú. Ha sido Asistente de Docencia de Teoría General del Proceso en la PUCP. Especialista en Derecho Procesal, Derecho de Arbitraje y Procedimiento Administrativo, con publicaciones en diferentes revistas nacionales. Actualmente labora en el área administrativa del Poder Judicial.

${ }^{250}$ RAMOS MENDEZ, Francisco. El sistema procesal español. José María Bosch Editor, Barcelona, 1997; p. 1

${ }^{251}$ GoZAínI, Osvaldo, Métodos diferentes del proceso para resolver conflictos entre personas: ¿es un tema procesal?, en “Teoría unitaria del derecho procesal”, Rosario, Juris, 2001, p. 50 
Sabido es que el hombre es un ser social que no vive aislado sino que vive en sociedad y que en esa vida de relación se encuentra regulado y, o reglamentado por algún orden, es decir alguna forma de Derecho Objetivo. Concebir que el hombre viva aislado o fuera de sociedad alguna, es pensar en un ser superior o en un degenerado como lo reconocía Aristóteles, pues, desde que el hombre empezó a vivir en sociedad, el conflicto ha coexistido con él, como una respuesta natural a la limitación de recursos, a la insatisfacción de necesidades, a la defensa de valores y a equivocadas percepciones, fruto de deficientes tipos de comunicación. Entonces, el conflicto es parte inherente a la relación existente entre los hombres y como tal se expresa en las diversas manifestaciones de la vida social, sea en el trabajo, en el hogar, en la vida afectiva, etc.

El conflicto constituye una constante situación que se encuentra inherente en todo grupo humano o sociedad. Tanto que, sin exagerar, podría ser considerada como natural a la condición humana. El ser humano tiene una doble dimensión. Por un lado, es un ser gregario, que no puede desarrollarse plenamente si no es en comunidad; por otro lado, posee una dimensión individual, desde que cada persona constituye una singularidad provista de valores, creencias y sentimientos que las convierten en un ser único e irrepetible. Por ello, concluye Roque Caivano que: "Estas dos características hacen que las situaciones de conflicto sean inevitables. Compartir un ámbito físico común, convivir entre semejantes, y ver la vida a través de su propia perspectiva y con su propio esquema cultural, hará que inexorablemente surjan conflictos. La existencia de conflictos en el seno de cualquier sociedad, en definitiva, forma parte de la realidad" 252 . Aunque no sean deseados, los conflictos deben ser esperados, como la consecuencia natural de la convivencia.

El orden social se asienta sobre la armonía y la concordia para que el individuo pueda desarrollarse. La sobrevivencia del grupo como tal exige una convivencia pacífica; pero no por ello puede pensarse que para logar esta paz, se produzca una situación de total ausencia de conflictos. Siendo un fenómeno natural, las sociedades deben asumir que tarde o temprano, en mayor o menor cantidad o intensidad, los conflictos aparecerán.

Debe precisarse que lo que perturba el desarrollo social y quebranta la paz y armonía en la sociedad no es tanto la existencia de los conflictos, que en el fondo constituye un fenómeno natural e inevitable inherente a todo ser humano, sino la falta de medios adecuados para resolverlos, lo que conduce al predominio de la violencia. "En otras palabras, una sociedad no debería aspirar a la inexistencia de conflictos (objetivo imposible, por definición), sino disponer de fórmulas eficaces para solucionarlos, asegurándose un grado razonable de equilibrio en las relaciones intergrupales. En la medida que existan mecanismos efectivos para resolver los conflictos y que exista una cultura social que incentive a los individuos a utilizar los más provechosos -para sí y para el conjunto- la comunidad tendrá más posibilidades de perdurar y ofrecerá mejores condiciones de vida a sus integrantes"253. Previo proceso educativo, la sociedad debería internalizar la conveniencia de una solución consensual en lugar de recurrir fácilmente a la violencia.

${ }^{252}$ CaIVANo, Roque, Los Medios Alternativos de Resolución de Conflictos en América latina: Logros y desafíos. Revista Peruana de Análisis, Prevención y Gestión de Conflictos, de la Pontificia Universidad Católica del Perú, Año 1, N 1, septiembre de 2007, p. 50.

${ }^{253}$ CAIVANO, Roque. Ob. cit., p. 52 


\section{Definición de conflicto}

Una primera aproximación a la idea de conflicto parte en reconocer que las crisis humanas se basan en la colisión de intereses. Es verdad que tal enfrentamiento puede tener múltiples explicaciones (escasez de los bienes de la vida, sometimiento de los débiles por los más fuertes, etc.), pero el conflicto se produce por el choque o la colisión de dos partes por diversos factores o actividades incompatibles entre sí, primando el antagonismo entre ellas.

El conflicto ha sido definido y estudiado desde diversas disciplinas, pero a continuación solo se va a enunciar aquellas que tiene alguna relevancia jurídica.

\subsection{Definición por los especialistas en Gestión de Conflictos}

Marianella Ledesma Narváez cita varias definiciones de conflicto. Así Folberg y Taylor "definen el conflicto como un conjunto de propósitos, métodos o conductas divergentes" 254 , para Boulding "el conflicto es una situación de competencia en la que cada una de las partes, conscientemente desea ocupar una posición que es incompatible con los deseos de otra" 255 . Según Pruitt y Rubbin "el conflicto es la divergencia percibida de intereses o creencias que hace que las aspiraciones corrientes de las partes no puedan ser alcanzadas simultáneamente" 256 . Por su parte Boardman y Horowitz "definen al conflicto como una incompatibilidad de conductas, cogniciones y/o afectos entre individuos y grupos que pueden o no conducir en una expresión agresiva de su incompatibilidad social" 257 .

Definido el conflicto en sentido técnico, como "una percibida divergencia de intereses", para que haya conflicto bastará que alguna de las partes perciba, sienta, que sus intereses no son compatibles con los de sus ciudadanos "258, sentido que tomaremos en cuenta.

\subsection{Definición de los procesalistas a partir de la teoría del litigio de Carnelutti}

Carnelutti fue uno de los máximos representantes de la dogmática italiana del pasado siglo e insigne procesalista, cuyas enseñanzas iluminaron la ciencia procesal por casi un siglo, es aquel el autor de la famosa teoría del litigio (constructor del famoso concepto de "litis" ${ }^{\text {259 }}$ ), para quien el proceso no tiene otra finalidad que la composición de litigios para lograr la paz social en justicia. "Las necesidades de los hombres son ilimitadas y los bienes son limitados. Desdichadamente los bienes, mientras satisfacen ciertas necesidades, estimulan otras. Para distinguir al hombre de los demás animales, acaso la fórmula más satisfactoria fuera decir que el hombre no está nunca contento. Cuanto más tiene, más quisiera tener, 260 Partiendo de la existencia del hombre en convivencia con otros hombres se producen colisiones entre ellos, dado que si tomamos a cada hombre en relación con un determinado objeto o bien de la vida, relación que es conocida con el nombre de interés; al

${ }^{254}$ LEDESMA NARVAEZ, Marianella., Un Conflicto conciliado: una visión jurídica de los elementos sustantivos. En: Revista Bibliotecal. Dirección de Biblioteca y Centro de Documentación del Colegio de Abogados de Lima; Año1, N 2, Lima, diciembre, 2000; p. 76.

255 Ibid.

${ }^{256}$ Ibid

${ }^{257}$ Ibid

${ }^{258}$ CAIVANO, Roque. Ob. cit., p. 51.

${ }^{259}$ Concepto que él mismo modificó y en parte abandonó finalmente.

${ }^{260}$ CARnElutTi, Francesco. Como nace el Derecho. Traducción de Santiago Sentís Melendo y Marino Ayerra Redín; Cuarta reimpresión de la tercera edición. Editorial Temis S.A., Bogotá; 2004; p. 9 
choque de intereses producido al entrecruzarse una pretensión con una resistencia se conoce como litigio. Así, "el litigio está presente en el proceso como la enfermedad está en la curación. El proceso consiste fundamentalmente, en llevar el litigio ante el juez, o también en desenvolverlo en su presencia (...) El litigio no es el proceso pero está en el proceso, ha de estar en el proceso si el proceso ha de servir para componerlo. De ahí que entre proceso y litigio medie la misma relación que entre continente y contenido" ${ }^{\text {261. }}$.

Es evidente que cada persona tiene una multitud de deseos que anhela satisfacer, mas habida cuenta de que los medios materiales para lograrlos son limitados, surge de inmediato una competencia entre los hombres origen muy a menudo de conflictos. Solo el hombre reunido en sociedad puede tener conflictos que interesan al Derecho. Definido el interés por Carnelutti como la situación favorable en que se encuentra un hombre (un sujeto) frente a un bien, en cuanto e es idóneo a la satisfacción de una necesidad suya; partiendo como primer enunciado que las necesidades del hombre son ilimitadas, y como segundo enunciado que los bienes para satisfacer dichas necesidades son escasos, entonces surge conflicto entre dos intereses cuando la situación favorable a la satisfacción de una necesidad excluye la situación favorable a la satisfacción de una necesidad distinta. Cuando el Derecho Objetivo privilegia o escoge un interés aquello se denomina derecho subjetivo que no es más que un interés protegido por el Derecho.

Las clases de conflictos que son pasibles de presentarse en la Teoría de Carnelutti son los siguientes:

a).- Conflicto intra-subjetivo: Es aquel que se produce dentro del fuero interno del sujeto, especialmente cuando el sujeto es el hombre individualmente considerado. La resolución del conflicto se produce con el sacrificio de un interés sobre otro, decisión que es obra de la voluntad del propio sujeto.

b).- Conflicto inter-subjetivo: constituye el punto central del fenómeno jurídico y propio del Derecho privado. Los conflictos intersubjetivos surgen como consecuencia de la vulneración de algún derecho subjetivo perteneciente al ámbito de derecho privado y poseen naturaleza disponible. Son los que surgen entre sujetos y versan sobre bienes disponibles, es decir, pertenecen a uno de ellos por lo que incumben al derecho privado.

\subsection{El conflicto como patología jurídica}

El Derecho Objetivo es el conjunto de normas jurídicas de conducta que hacen posible la vida en común y resultan indispensables para su regulación ${ }^{262}$. Como el hombre es miembro de un grupo social, vive en sociedad, necesita de reglas para la convivencia armónica entre los distintos sujetos. El Derecho nos brinda herramientas para lograr la satisfacción de nuestros propios intereses. Estas herramientas o instrumentos son:

a).- Derechos subjetivos: Establece una titularidad respecto a un sujeto (asignada a un sujeto) en relación a otro u a otros y estos últimos se encuentran obligados a reconocer dicha titularidad.

261 CARnelutTI, Franceso. Sistema de derecho Procesal Civil.Trad. De Niceto Alcalá-Zamora y Santiago Sentís Melendo; Uteha; Buenos Aires; 1944; p. 3.

${ }^{262}$ VÉSCOVI, Enrique. Teoría General del Proceso, Editorial Temis Librería, Bogotá, 1984, p. 3 
b).- Intereses legítimos: Este tipo de facultad para solicitar algo se encuentra reconocida por el Derecho. La diferencia radica en que en el interés legítimo no existe titularidad de algo respecto de otro, sino que una norma deba ser cumplida cuando alguien pida su cumplimiento.

Por ejemplo, si A tiene una casa frente a la playa y un buque cisterna petrolero arroja su petróleo al agua, contaminando el litoral afectando a " $\mathrm{A}$ " y al mar peruano. En este caso, al dañar la propiedad (casa de playa) se dice que A tiene un derecho subjetivo, y al ser dañado el mar peruano (atentado contra normas ambientales) cualquier afectado tiene un interés legítimo.

El Derecho es un conjunto de reglas que regulan la conducta humana. El conjunto de reglas es también un conjunto de normas jurídicas. El Derecho regula derechos subjetivo e intereses legítimos; entonces al sistema procesal se accede solo cuando hay conflicto es decir cuando se vulnera un derecho subjetivo o un interés legítimo.

Para esta posición hay tres tipos de conflictos que gozan de aceptación unánime:

a).- Conflictos intersubjetivos: Los conflictos intersubjetivos surgen como consecuencia de la vulneración de algún derecho subjetivo perteneciente al ámbito de derecho privado y poseen naturaleza disponible. Estos conflictos versan sobre bienes disponibles, es decir, pertenecen a uno de ellos y por ende son propios del derecho privado.

b).- Conflictos sociales: Los conflictos sociales se caracterizan por la trasgresión de algún bien o interés que la sociedad ha estimado digno de protección (delitos e infracciones administrativas) y se rigen por las normas de derecho público, por lo que poseen una naturaleza indisponible. Se dan respecto de un sujeto frente a la sociedad en su conjunto, por lo tanto, son conflictos que recaen sobre bienes no disponibles propios del derecho público.

c).- Conflictos mixtos: Parte como un conflicto entre dos partes pero a la sociedad y al Derecho tiene un interés. Un ejemplo es el divorcio, donde la sociedad busca que prevalezca la familia como núcleo social elemental de la sociedad, es por eso este conflicto se hace social e indisponible.

Modernamente no se habla de conflicto sino de patología jurídica. Siendo el Derecho un conjunto de normas jurídicas que regulan un derecho subjetivo o un interés legítimo, si se produjera la vulneración de una norma jurídica se dice que entra en un supuesto de patología jurídica a causa de la vulneración de la norma.

De todas las expresiones de conflicto, solo interesan al Derecho aquellas que sean relevantes jurídicamente. "Decimos que son conflictos sin trascendencia jurídica porque los supuestos no están contenidos en ninguna norma jurídica de nuestro ordenamiento" 263 tales como una competencia deportiva o una entrevista psicológica; por otro lado, "un conflicto de intereses tiene relevancia jurídica cuando la materia de los intereses resistidos, está prevista

${ }^{263}$ LEDESMA NARVAEZ, Marianella; Ob. cit., p. 76 
dentro del sistema jurídico de una sociedad políticamente organizada"264 como pueden ser el hijo que reclama alimentos al padre, o el acreedor que exige la deuda al obligado.

\subsection{Solución del conflicto}

Es justo reconocer, que "la conducta humana se ajusta normalmente al derecho, que por otra parte, recoge como norma la regla social, esto es, lo que habitualmente se cumple; los conflictos, pues, de ordinario no se producen, pero en caso de ocurrir, también, generalmente, se da y para los casos de excepción (pese a ser muchos, son de gran excepción) el Estado resuelven por la vía pacífica. No obstante debe establecer su tutela jurídica, es decir la prestación de apoyo y el establecimiento de formas para que se respeten las situaciones jurídicas legítimas y se cumpla con el derecho",265.

La primera forma de resolver conflictos se orienta a un sistema adversarial porque generalmente se piensa que los conflictos son destructivos y se plantea como única opción perder o ganar. El proceso judicial es una clara muestra de esta forma de solución, por lo que debe encontrarse otras figuras de menor encuentro conflictivo, donde la técnica de resolución y la del debate permita concertar voluntariamente sin que ninguno de los litigantes se encuentre obligado a recurrir al servicio que se ofrece, como sí ocurre con el proceso judicial. La idea simple que se propone es abandonar la discusión permitiendo soluciones a partir de actitudes voluntarias.

Habitualmente el esquema de solución de un conflicto por un abogado es derivar hacia un tercero la solución, presentando su posición como una cuestión de pretensiones. Y es normal que un abogado piense de esa manera, basta revisar los currículos de las Facultades de Derecho, de décadas pasadas para darnos cuenta que la resolución de conflictos se aborda únicamente a través del estudio y aplicación del derecho procesal. La demanda judicial resulta ser así el recurso más usado a fin de iniciar el proceso que componga el conflicto. Siendo un problema o conflicto definido ya entre dos adversarios, ya no habrá más posibilidades de conversar que las hipótesis infrecuentes de las audiencias, máxime si el proceso se rige por el principio de escritura. Así se ha asumido sin mayor discusión el sistema adversarial.

El proceso judicial en el cual el Estado ejerce su potestad jurisdiccional es un caso típico de la resolución de un conflicto basado en el sistema adversarial. Con la aparición del Estado Nacional, el Estado moderno hoy es el dueño de la facultad sancionadora; sin embargo, no siempre la función jurisdiccional (solucionar conflictos mediante la aplicación del derecho pertinente) ha sido sometida a los órganos jurisdiccionales, ni puede afirmarse hoy que la asumen con absoluta exclusividad pues coexiste con otros métodos o formas de resolver un conflicto, ni tampoco puede afirmarse que así será en el futuro. Al individuo se le prohíbe la justicia por mano propia, es decir se le pide renunciar a su libertad, y a cambio de esta restricción, se brinda a los ciudadanos un sistema de tutela jurídica organizado y costoso. Se prepara una infraestructura (Tribunales y jueces) y se regula los instrumentos para brindar tutela jurídica a través del proceso.

\footnotetext{
${ }^{264}$ LEDESMA NARVAEZ, Marianella; Ob. cit., p. 77

${ }^{265}$ VÉSCOVI, Enrique. Ob. cit., p. 3
} 
Esa ha sido la forma tradicional de resolución de conflictos en el mundo, por el contrario hoy en día se pretende virar hacia otra forma de enfrentar el conflicto. Se busca asumir el conocimiento del conflicto en todos sus aspectos y dimensiones, revirtiendo la actitud del abogado que estudia el caso para someterlo al proceso. El abogado debe abandonar los conceptos adversariales y someterse a esta nueva concepción de encarar los conflictos. Así "cuando hablamos de conocer el conflicto para negociar sobre el mismo, relegar la dimensión personal del entuerto para encontrarle ventajas compartidas y olvidarse del éxito individual para solidarizar las soluciones, estamos pensando en la estimativa social que tienen los acuerdos que pacifican rápidamente las crisis entre partes" "266. Nos dice sobre lo mismo Ledesma Narváez: "El mensaje que se pretende brindar es que el proceso judicial no sea la única opción que se valore en la solución del conflicto, sino que, debe privilegiarse otras alternativas como la conciliación, atendiendo a las circunstancias y naturaleza de cada conflicto a operar" ${ }^{, 267}$.

Surgen así los denominados "Medios alternativos de resolución de conflictos" en inglés ADR (Alternative Dispute Resolution), pero siendo honestos dogmáticamente el principal medio sigue siendo el proceso.

Uno de los problemas a tomar en cuenta es la propia denominación de Medios Alternativos de Resolución de Conflictos. El calificativo de "alternativos" alienta la confusión. Se piensa que por su carácter alternativo son subsidiarios, secundarios o accesorios en relación al proceso judicial. Entonces si aquellos son alternativos, es porque se atribuye al proceso judicial un carácter de principal o natural. Pero el nombre dado es simplemente por exclusión al proceso.

Debe entenderse que no existen medios principales o naturales, ni secundarios o alternativos, lo que existen son métodos sin más, y si es necesario ponerles un calificativo, y este debería ser "adecuado" o "apropiado" pues "en definitiva, cada conflicto tiene determinadas características, unos actores y un contexto que llevan a recomendar la utilización de un método particular para resolverlo" ${ }^{268}$.

Uno de los primeros problemas a considerar es sobre la naturaleza jurídica que se reconoce a estas vías:

a) Se consideran vía alternativas al proceso jurisdiccional, esto es, una opción dada a quien pretende demandar a otro, quien puede elegir un método de solución distinto al que ofrece el juicio jurisdiccional ordinario. Posición de carácter ideológico, que considera que ante una justicia en crisis, cabe la alternativa momentánea de los métodos alternativos.

b) Hay quienes estiman que la posibilidad de opción se limita a una cuestión personal, una simple elección por una vía que en realidad, es un equivalente del proceso común.

c) Otros consideran que son procedimientos que sustituyen la actuación judicial y que generan un impedimento para el acceso a la justicia y que, por tanto, deviene

\footnotetext{
${ }^{266}$ GOZAINI, Osvaldo. Ob. cit., p. 33

${ }^{267}$ LEDESMA NARVAEZ, Marianella. Ob. cit., p. 80

${ }^{268}$ CAIVANO, Roque. Ob. cit., p. 58
} 
inconstitucionales pues la resolución de conflictos es una tarea -afirman- de los Jueces de la Nación ${ }^{269}$.

El meollo del tema es dilucidar si estas instituciones que denominamos alternativas, pretenden o sustituir o colaborar con la justicia. Podría pensarse que la existencia de estos medios alternativos tiene como finalidad eliminar el proceso civil pero ello no es así, la finalidad inmediata es solo coadyuvar o cooperar a que la administración de justicia se torne más rápida y eficiente permitiendo al proceso civil conseguir sus fines. Los llamados medios alternativos de resolución de conflictos complementan el funcionamiento adecuado de los mecanismos jurisdiccionales, a los cuales se debe acudir en última ratio, esto es cuando se hayan agotado los medios para intentar resolver el conflicto de una manera directa a través de fórmulas que ayuden a descongestionar la inmensa carga procesal que agobia al Poder Judicial, actuando como filtros que solucionen los casos solubles y dejan para este aquellos que requieran de manera indefectible de un pronunciamiento de este poder.

Obviamente la finalidad mediata será eliminar el proceso como forma de resolver conflictos cuando su estadio de evolución sea el propicio.

Antes de 1990, la mayoría de métodos que hoy se conocen como "Medios Alternativos de Resolución de Conflictos" eran corrientemente desconocidos por los abogados y demás gestores de conflictos. Desde el punto de vista normativo, únicamente existían regulaciones legales anticuadas contenidas en el Código Civil sobre arbitraje y conciliación, como un procedimiento desarrollado por y ante un juez dentro del marco de un proceso jurisdiccional. No existían normas sobre conciliación ni mucho menos otros métodos. Y los métodos existentes eran poco difundidos, generalmente desconocidos, y por ende escasamente utilizados.

Durante la década de los noventas en América latina, casi todos los países habían ya advertido el déficit en estos temas. Así, "comenzó a producirse un rápido movimiento, que se materializó en dos grandes líneas de acción: por un lado, se dio recepción legislativa a estos instrumentos, con diferentes enfoques y perspectivas; por el otro, se gestaron inactivas tendientes a su divulgación, también con orientaciones variadas" ${ }^{\text {"270 }}$. En el plano legislativo, algunos países sancionaron directamente normas sobre la materia, ya sea legislando simultáneamente los métodos en una misma ley, o legislando los principales métodos a través de leyes separadas; o actualizando las vetustas. En el plano de la difusión, el trabajo ha sido encarado tanto desde las instituciones públicas como de las privadas, ya sea mediante divulgación del sistema, formación de profesionales, implementación de los métodos por instituciones profesionales y empresariales, o por medio de cursos dictados en pre grado y post grado en las universidades.

La conclusión del fenómeno es evidente: cada vez está más internalizado que el tratamiento de los conflictos no es monopolio exclusivo de los tribunales judiciales y que existen otras formas de solución.

Pero la decisión de recurrir al uso de los Medios Alternativos de Resolución de Conflictos no debe hacerse por el solo hecho de escapar del abarrotado sistema judicial, sino por el contrario, "esta decisión debe estar sustentada en la convicción de que el método

\footnotetext{
${ }^{269}$ GoZAINI, Osvaldo Alfredo. "Métodos diferentes al proceso para resolver conflictos entre personas: ¿son un tema procesal?; p. 31.

${ }^{270}$ CAIVANO, Roque. Ob. cit., p. 53.
} 
escogido es mejor que cualquiera de los otros disponibles y que permitirá solucionar el conflicto de la forma más eficiente". Con ello, al mismo tiempo que se obtendrá una mayor satisfacción de los intereses de los protagonistas, se logrará mantener una armónica convivencia, objetivo de interés general. Con la elección de un método apropiado se conseguirá un resultado individual y socialmente más valioso"271.

Pese a que los Medios Alternativos de Resolución de Conflictos más conocidos son la conciliación y el arbitraje, no debe creerse injustificadamente que sean los únicos, por eso, los estudiosos del tema (y se debe este mérito a los procesalistas), han establecido la siguiente clasificación para la solución del conflicto:

- Auto tutela

- Autocomposición

- Heterocomposición

Veamos a continuación, brevemente cada una de ellas.

\section{Autotutela}

La fuerza es la más antigua y natural manera de resolver los conflictos como tendencia primitiva del ser humano, pero la evolución social y jurídica va excluyendo la fuerza en la medida que se presenta el progreso cultural y humano. Podemos identificar la evolución como rechazo a la fuerza como solución.

Esta forma de resolver un conflicto también recibe otros nombres en doctrina tales como autodefensa, autoayuda o auto justicia.

La trayectoria histórica de la autodefensa no ha marchado de manera constante a su extinción. Así pues la prohibición de la autodefensa, establecida en forma general por el derecho romano (Dig. IX, 2, 45 y Dig. XLVIII, 7, 7) desaparece en el periodo medieval y también en la edad moderna, en que las bárbaras concepciones de origen germano pusieron en boga por varios siglos, como forma de resolución de conflictos, el duelo y la venganza. Solo en las legislaciones contemporáneas, a través del influjo del derecho canónico, la prohibición vuelve a ser general y absoluta.

La autotutela es aquella forma de solución en la cual uno de los sujetos resuelve el mismo de manera unilateral el conflicto, imponiendo su voluntad a la contraparte. Se dice que la solución se da por mano propia o a través de una acción directa. Esa forma la podemos llamar autodefensa (defensa propia) en virtud de la cual el titular de la situación (o del derecho) asume la defensa de ella",272

La autodefensa es la defensa más antigua, primitiva, natural, injusta, peligrosa y simple. Es la expresión natural, espontánea, instintiva del sujeto para utilizar la fuerza cuando ve lesionado su interés por la acción de otro sujeto. Su empleo es simple porque para su ejercicio no requiere de la intermediación de ninguna otra persona y menos de algún tipo de organización estatal.

Presenta como características:

${ }^{271}$ CAIVANO, Roque. Ob. cit., p. 52

${ }^{272}$ VÉSCOVI, Enrique. Ob. cit., p 04 
- Ausencia de un tercero distinto a las partes con capacidad para decidir el conflicto

- Una de las partes (la que decide el conflicto a su favor) tiene una situación de dominio, hegemónica o ventaja o fuerza sobre otra.

Dado el desarrollo actual del Derecho convine preguntarse ¿Cuál es la razón de su reconocimiento en los ordenamientos?, la respuesta más apropiada sería que el Estado termina por reconocer la autodefensa como solución cuando su propia actividad no llega o puede llegar muy tarde.

Pese a la tendencia de abolición o prohibición de la autodefensa, se mantiene residualmente la autodefensa, pero estableciéndose como regla su carácter excepcional. Si partimos de la idea que la autodefensa pasó a ser una forma ilícita de resolver conflictos desde que tal función se atribuyó al Estado, concluimos que la autodefensa no es la generalidad sino la excepción como forma de resolver los conflictos, por eso excepcionalmente, la Ley autoriza en algunos casos el empleo de la autodefensa, deviniendo de esta manera su utilización para estos pocos casos en lícita y legítima; pero regularmente suelen ser proscritas por los ordenamientos, ya sea como delitos o garantizando ampliamente el ejercicio de la tutela jurisdiccional efectiva.

Los actos de autodefensa que existen en la ley son pocos. Así, son manifestaciones lícitas de este tipo reguladas en la ley las siguientes:

- En Derecho Penal: La legítima defensa y el estado de necesidad (art. 20 del $\mathrm{CP}^{273}$ ).

- En Derecho Laboral: La huelga o el cierre patronal.

- En Derecho internacional: La guerra, dada la inexistencia de un Estado mundial o supranacional.

- En Derecho Civil:

○ Derecho de retención (art. 1,123 del $\mathrm{CC}^{274}$ )

- Exceptio de non adimpleti contractus (art. $1426 \mathrm{del} \mathrm{CC}^{275}$ )

- La posibilidad de cortar árboles o plantas de mi vecino que invadan mi predio (art. 967 del $\mathrm{CC}^{276}$ )

- Defensa posesoria (art. 920 del $\mathrm{CC}^{277}$ )

${ }^{273}$ Código Penal Artículo 20.- Esta exento de responsabilidad penal: (...) 3.- El que obra en defensa de bienes jurídicos propios o de terceros, siempre que concurran las siguientes circunstancias: a) Agresión ilegítima; b).-Necesidad racional del medio empleado para impedirla o repelerla; y c).-Falta de provocación suficiente de quien hace la defensa; 4.-El que, ante un peligro actual e insuperable de otro modo, que amenace la vida, la integridad corporal, la libertad u otro bien jurídico, realiza un hecho destinado a conjurar dicho peligro de si o de otro, siempre que concurran los siguientes requisitos: a). Cuando de la apreciación de los bienes jurídicos en conflicto afectados y e la intensidad del peligro que amenaza, el bien protegido resulta predominante sobre el interés dañado; $\mathrm{y} b$ ).- Cuando se emplee un medio adecuado para vencer el peligro.

${ }^{274}$ Código Civil Artículo 1123.- Por el derecho de retención un acreedor retiene en su poder el bien de su deudor si su crédito no está suficientemente garantizado. Este derecho procede en los casos que establece la ley o cuando haya conexión entre el crédito y el bien que se retiene.

${ }^{275}$ Código Civil: Artículo 1426.- En los contratos con prestaciones recíprocas en que éstas deben cumplirse simultáneamente, cada parte tiene derecho a suspender el cumplimiento de la prestación a su cargo, hasta que se satisfaga la contraprestación o se garantice su cumplimiento.

${ }^{276}$ Código Civil: Artículo 967.- Todo propietario puede cortar las ramas de los árboles que se extiendan sobre el predio y las raíces que lo invadan. Cuando sea necesario podrá recurrir a la autoridad municipal o judicial para el ejercicio de estos derechos. 
En el estado actual de nuestro desarrollo jurídico, conviene preguntarse si debe desaparecer la autodefensa. Al respecto, si bien algunos estudiosos del proceso consideran a la autodefensa como un mal que debe desaparecer de los ordenamientos, consideramos que esa idea es inviable porque los sistemas existentes de resolución de conflictos principalmente el estatal - no son aún perfectos como desearíamos y además, considerando la masificación del uso del proceso como principal medio de resolución de conflictos, este dista mucho de poder someter a cauces procesales la totalidad de los conflictos, por lo que le conviene autorizar o aprovechar salidas legales que liberen a sus órganos judiciales del mayor número posible de litigios. Frente a este escenario, si se eliminaría toda forma de autodefensa, cabe cuestionarse si estarían los órganos judiciales preparados para disponer de un servicio efectivo ante el congestionamiento que se produciría.

La autodefensa tiene lugar al margen del proceso, por ello no está precedida por el ejercicio de la acción ni admite instituciones procesales, pues sin perjuicio que su validez pueda ser discutida posteriormente en un proceso, ninguna expresión de autodefensa produce el efecto de cosa juzgada.

Empero el permitir la autodefensa, encierra riesgos que se encuentran en parte neutralizados mediante dos correctivos importantes: la procesalización y la homologación judicial. " $[L]$ a procesalización de alguna de sus formas tiende a obtener una decisión justa y la homologación judicial, tiene por objeto comprobar su justicia, precisamente para eximir de sanción" ${ }^{279}$.

\subsection{Autocomposición}

El segundo sistema de solución de conflictos se denomina autocomposición, que se caracteriza porque solo la voluntad de las partes involucradas en el mismo va a ser lo único que ponga fin al antagonismo. Es decir, ambas partes resuelven sus conflictos formulando una solución arribada por ellas mismas sin que una se imponga sobre la otra. "Al igual que el sistema de autodefensa, la autocomposición en un sistema parcial de solución de conflictos, porque van a ser las propias partes involucradas en el conflicto las que van a buscar la solución ${ }^{, 280}$.

Las formas que esta clasificación propone se basan en el acuerdo de voluntades o el voluntario sacrificio o resignación de alguna de las partes y son las siguientes:

- Allanamiento: Es la sumisión del atacado (pretendido, demandado) que se aviene a reconocer la razón (o la pretensión) de otro.

${ }^{277}$ Código Civil: Artículo 920.- El poseedor puede repeler la fuerza que se emplee contra él y recobrar el bien, sin intervalo de tiempo, si fuera desposeído, pero en ambos casos debe abstenerse de las vías de hecho no justificadas por las circunstancias.

${ }^{278}$ Código Civil: Artículo 423.- Son deberes y derechos de los padres que ejercen la patria potestad:

(...) 3. Corregir moderadamente a los hijos y, cuando esto no bastaré recurrir a la autoridad judicial solicitando su internamiento en un establecimiento dedicado a la reeducación de menores.

279 Afirma Ledesma Narváez que no basta que se afirme que se ha matado a alguien en legítima defensa, cuando los hechos aparezcan objetivamente contemplados como punibles, sino que habrá de ser contemplados judicialmente tales extremos. Si bien la autodefensa es por definición decisión parcial del conflicto puesto que la impone una de las partes en litigio no se puede sostener que represente victoria de la prepotencia sobre la justicia.

${ }^{280}$ LEDESMA NARVÁEZ, Marianella. Ob. cit., pp. 79-80 
- Renuncia o desistimiento: El atacado abandona el conflicto sacrificando su propio interés.

- Transacción: Derivada de un acuerdo entre ambas partes en conflicto, las cuales lo resuelven mediante concesiones recíprocas en sus respectivos intereses o pretensiones.

\subsection{Heterocomposición}

La heterocomposición tiene como característica esencial la terceridad, esto es, que una persona ajena a las partes va a decidir el conflicto. Dado que el conflicto no pudo resolverse ni por voluntad de uno, ni por los dos, por lo cual deviene en necesaria la presencia de un tercero en el conflicto, donde el tercero tiene por misión resolver (o ayudar a resolver) el conflicto planteado.

Se tiene la siguiente clasificación dentro de este tipo de métodos:

- Formas horizontales
- Mediación
- Conciliación.

\section{- Formas verticales}
○ Proceso
- Arbitraje.

\subsubsection{Figuras horizontales}

En este tipo de figuras el tercero decide con las partes.

\section{a) Mediación}

El mediador es un tercero que intenta acercar y comunicar a las partes entre sí y luego los reúne. Este tercero propone medios de solución al conflicto aceptables por lo que puede lograr el acuerdo entre las partes sobre la discrepancia, siendo el tercero un simple particular que interpone sus buenos oficios. El acuerdo es eficaz porque se materializa en un contrato o una transacción normalmente.

Cabe diferenciar esta figura de la conciliación. Etimológicamente, la voz conciliación proviene del latín "conciliare", que significa componer y ajustar los ánimos de los que están opuestos entre sí, ponerlos en paz. En cambio, la palabra mediación, proviene del latín "mediare", que significa interponerse. Tanto en la conciliación como en la mediación connotan la existencia de un tercero que interviene en un conflicto asumiendo roles distintos. Mientras que el conciliador eventualmente propone fórmulas de solución no obligatorias que ayuda a las partes a llegar a un acuerdo; el mediador no tiene facultad para proponer opciones de solución al conflicto, solo es un facilitador de la comunicación y evita mayor conflictividad entre ellas.

\section{b) Conciliación}

En palabras de Marianella Ledesma, "la conciliación, constituye uno de esos medios, por el cual un tercero imparcial interviene en el conflicto, con el consentimiento de las partes, para ayudarles y facilitarles la obtención de algún acuerdo que satisfaga los intereses de las partes enfrentadas. La importancia de esta intervención reside en que sólo 
las partes y nadie más que ellas, son las que definen el resultado que quieran atribuir al conflicto que las separa. El poder de decisión está en las partes y no en el tercero conciliador, quien interviene como un mero avenidor o facilitador de la comunicación. Es pues el binomio, conflicto y voluntad, los pilares sobre el que se construye la conciliación" ${ }^{, 281}$.

En el Perú, coexistían la conciliación judicial y la conciliación extrajudicial (que se mantiene vigente), con la peculiaridad de que ambas eran obligatorias.

El primer contrasentido de la institución es que siendo un sistema que permite aligerar la carga de tensión y eliminar cierta animosidad o enemistad hacia la contraparte para convertirla en un medio de acercamiento y pacificación, parece insostenible tolerar la obligatoriedad dispuesta por ley, cuando la confianza no se impone.

En Argentina también impuso un sistema de conciliación (mediación) obligatoria, y todas las voces se alzaron contra esta medida ${ }^{282}$ con los siguientes argumentos: $i$ ) por ser contraria a una de sus características que es la voluntariedad y limitando la oportunidad de gestión al momento previo de la litis; ii) procura descongestionar el Poder Judicial llevando al Estado a desertar de su función de administrar justicia; y iii) dicha medida no tiene parangón en el Derecho comparado.

Al respecto, exponemos dos precisiones sobre la conciliación extrajudicial:

"El procedimiento encausado dentro de los medios alternativos no es un proceso; técnicamente el juicio es otra cosa, se vincula con la actividad gnoseológica del juez destinada a subsumir los conceptos jurídicos que las partes han desarrollado en los actos de procedimiento desde la postulación de sus pretensiones" 283 .

"Con ello queremos expresar que si la función de mediador, conciliador o árbitro no es jurisdiccional (es decir, no resuelve cono carácter obligatorio) las actuaciones debieran estar absolutamente fuera del proceso" 284 .

La norma que impone la obligatoriedad de someter a conciliación las controversias sobre derechos patrimoniales (que están dentro de la categoría de derechos disponibles) contiene una cuestionable constitucionalidad, dado que el artículo 62 segundo párrafo de la Constitución de 1993, que regula los principios generales del régimen económico consagra como únicas vías para la resolución de conflictos derivados de la relación contractual (y por ende de derechos patrimoniales) la arbitral y la jurisdiccional, quedando excluida la vía de conciliación por evidente omisión.

Como correlato no dejan de tener razón aquellos magistrados que restándole mérito de "título de ejecución" al acta de acuerdos abordados en Conciliación, le otorgan únicamente la calidad de medio probatorio adaptando la demanda a la vía procedimental que considere apropiada (sumarísima, abreviada o de conocimiento) en ejercicio de las facultades conferidas por el artículo 51 inciso 1 del Código Procesal Civil, accionar que tiene como fundamento precisamente el no reconocimiento de la conciliación extrajudicial como vía de

${ }^{281}$ LEDESMA NARVAEZ, Marianella. Ob. cit., p. 75

${ }^{282}$ GozAINI, Osvaldo Alfredo. Ob. cit., pp. 38-40

${ }^{283}$ GoZAINI, Osvaldo Alfredo. Ob. cit., p. 40

${ }^{284}$ GoZAINI, Osvaldo Alfredo. Ob. cit., p. 41 
resolución (definitiva, es decir con calidad de cosa juzgada) de conflictos por la constitución; por ende, se considera que el procedimiento conciliatorio no es más que uno que debe servir como medio de prueba.

Sin embargo, otras normas si refieren a la conciliación. La constitución dice que toda persona tiene derecho a la paz; el Código Procesal Civil menciona que la finalidad abstracta del proceso es lograr la paz social en justicia, y la Ley de Conciliación Extrajudicial, que la conciliación propicia una cultura de paz.

El tercero aquí busca el acercamiento entre las partes. Excepcionalmente propone una fórmula conciliatoria (art. 20 de la Ley $\mathrm{N}^{\circ}$ 26872). Es en cierto modo una mediación.

La restringida obligatoriedad de la conciliación extrajudicial no perjudica el derecho a la tutela jurisdiccional efectiva; antes bien podría hacerla innecesaria, al desaparecer el interés para obrar con el acuerdo total, como fruto de un buen procedimiento conciliatorio. Esto ahorraría al justiciable el tiempo, dinero y sufrimiento que implica todo proceso judicial.

Pero desde que en noviembre del año 2000 en el marco del Decreto Supremo No 007 2000 -JUS, que marcó del plan piloto de obligatoriedad de la conciliación extrajudicial que empezara a regular el requisito de obligatoriedad del intento conciliatorio en los distritos judiciales de Arequipa, Trujillo y Lima Norte, y posteriormente ampliada desde el 1 de marzo del 2001 mediante Ley $\mathrm{N}^{\circ} 27398$ a las ciudades de Lima y Callao, se empezaron a visualizar los problemas en la aplicación de la conciliación extrajudicial:

- Se incrementan los costos para el ciudadano.

- La resolución del conflicto dura más por ser la conciliación un trámite más que no genera resultados positivos.

- En el diseño normativo de la conciliación extrajudicial se percibe una fuerte influencia procesal. La actividad conciliatoria previa al proceso debe tener normas ligeras, flexibles, con una reducida influencia del derecho procesal, y no que se perciba como una instancia más de este, como un mecanismo previo. Al sentirse fuertemente procesalizada el justiciable necesita de un abogado que lo asesore.

- Aparición de nuevos casos de "leguleyadas".

- El trámite de conciliación resulta engorroso por las imprecisiones de la ley, pues la regulación de un trámite legal debe facilitar la justiciable su derecho a la tutela jurisdiccional efectiva. Empero los problemas que pueden presentarse en el irregular tránsito por la conciliación extrajudicial que impide luego acudir eficazmente al orden jurisdiccional, obliga a tener que recurrir nuevamente al mismo centro $u$ otro centro de conciliación a fin de cumplir cabalmente con la formalidad del trámite, es decir que ahora hay que llevar al cabo un trámite bien en dos vías, la jurisdiccional y la conciliatoria, so pena de las nulidades que en ambos casos se pudiera incurrir de no hacerlo.

- Se ha convertido en un trámite más. En los hechos nos encontramos con un medio de resolución de conflictos que constituye un trámite más para los justiciables en vista de obtener protección a sus derechos e intereses, trámite calificado más en el hecho de su 
excesivo reglamentarismo y a la excesiva importancia atribuida al cumplimiento de la formalidad bajo sanción de nulidad.

- La poca capacitación del conciliador en temas especializados, y su falta de compromiso con su labor, conlleva a la falta de interés de las partes por una solución consensuada constructiva y en vista de ello, la conciliación queda reducida al triste papeleo de un mero trámite, necesario para poder iniciar luego las acciones judiciales.

A la fecha no existe un estudio por parte de la autoridad competente - Ministerio de Justicia - que haya hecho una evaluación seria con información estadística confiable que corrobore la utilidad del sistema, que contenga por ejemplo, cuántas solicitudes de conciliación concluyeron satisfactoriamente sin tener que recurrir al Poder Judicial; cuántas concluyeron con acuerdos que fueron incumplidos y necesitaron recurrir al Poder judicial para exigir su cumplimiento, y finalmente cuántas concluyeron sin acuerdo por desavenencia entre las posiciones de las partes, o por su inasistencia a las audiencias, requiriendo por ende acudir al Poder Judicial para la resolución de su conflicto. Ahora bien este estudio no debería ser tan complicado como parece, habida cuenta que todos los centros de conciliación autorizados se encuentran bajo la supervisión del Ministerio de Justicia y al que bien pudieron alcanzar un informe con sus estadísticas, cuyos resultados consolidados hubieran podido arrojar tan valiosa información, con lo que hoy mismo no se cuenta, lo que me hace presumir que el desconocimiento de cifras, que podrían ser en el mejor de los casos desalentadoras, no es del todo ingenuo sino que obedece a un afán de encubrir el fracaso del sistema. Existe como fuente estadística los boletines estadísticos de la Secretaría de Conciliación del Ministerio de Justicia ${ }^{285}$, pero requiere un estudio debido.

Por otro lado, se han realizado estudios que abonan la justificación del empleo de la conciliación extrajudicial $^{286}$, resaltándose entre las razones:

- Un primer fundamento, de tipo filosófico, radica en el establecimiento de la llamada "cultura de paz" y propugna que en una sociedad, donde el conflicto se ha institucionalizado como manera de hacer respetar nuestros derechos, creando un clima de confrontación en la resolución de disputas, se debe aspirar a llegar a alcanzar una situación ideal en la que se mantenga la paz y la tranquilidad entre los miembros de esa sociedad. Afirmamos junto con Hilmer Zegarra que si el conflicto nace en los mismos coasociados, lo óptimo sería que la solución nazca igualmente de ellos, para eliminar esa secuela nefasta de todo juicio donde hay un ganador y un perdedor, en aras del interés común, optando por resolver pacíficamente su conflicto de intereses para así evitar un futuro proceso que podría entablarse, contando para ello con la ayuda de un tercero.

Por la conciliación extrajudicial se permitirá a todos los miembros de la sociedad civil que gocen de la capacidad de ejercicio, que puedan restablecer la paz social. Se ha permitido así revalorar la creatividad de las partes involucradas en el conflicto, se ha redimensionado su rol protagónico en relación con el Estado, pues, ya no es este el único que puede poner fin a los conflictos, sino que también puede compartir el escenario con el ciudadano.

\footnotetext{
${ }^{285}$ Ubicado en www.minjus.gob.pe/conciliación/estadística/situación.htm.

286 PINEDO AUBIÁn, Martín; Justificación del empleo de la conciliación extrajudicial. En Legal Express, Publicación Mensual de Gaceta Jurídica, N³9, Año 4, Marzo del 2004.
} 
-El segundo fundamento es más bien de orden operativo, afirmándose que los medios alternativos para la resolución de conflictos, propiciarán la descongestión del despacho judicial, haciendo que los casos que puedan ser solucionados por ejemplo vía conciliaciones previas o arbitrajes libremente pactados no lleguen a la esfera de acción del Poder Judicial, dejando su acción solamente a aquellos casos en que no sea posible una solución dialogada entre las partes para dar paso a un acto de decisión del conflicto por parte del juez mediante la expedición de la sentencia.

A nuestro entender son causas del fracaso de la conciliación extrajudicial obligatoria en el Perú:

- Nuestra sociedad privilegia el litigio judicial sobre los métodos alternativos de resolución de conflictos. Hay una cultura del litigio, de enfrentamiento frente a una cultura de paz. Pues la conciliación forma parte de una cultura de convivencia en armonía, al margen de la existencia del litigio. La forma de interrelacionarnos y responder a los conflictos de manera conciliadora debe operar en todos los ámbitos de la actividad humana. Llegar a ello implica internalizar respuestas de vida, las mismas que se van forjando, modelando con la educación, tanto en el hogar, escuela, iglesia y otras instituciones que tengan una fuerte incidencia en la formación del individuo. Es pertinente dejar una pregunta suelta, ¿El Estado ha diseñado una política educativa que despierte a todo nivel habilidades en el campo de la negociación o conciliación en la instrucción básica de sus ciudadanos?

- En la formación de los operadores jurídicos hay una preparación centrada en el litigio. En la mayoría de las facultades de Derecho se suele adiestrar al estudiante para afrontar con éxito un proceso, y no para orientar a su cliente a una salida negociada con su contraparte, lo cual es definitivamente más rápido y pacífico.

- Desconocimiento de la mayoría de la población de la conciliación por falta de divulgación. Los justiciables aún creen que el proceso judicial es la única vía a la que podrán recurrir para satisfacer sus pretensiones, pasando por alto que existen otras formas de solución.

- Los abogados también son parte del problema. Entre ellos existe una predisposición innata de resistencia a la conciliación obligatoria. La verdad que ellos no les interesa esta opción pues consideran que el proceso es y seguirá siendo el instrumento ideal, y si es posible el único, para la solución de conflictos. La explicación de esta vehemencia procesal de los abogados tiene diferentes factores. El abogado común -que es su mayoría es litigante- vive del litigio, si este es de mayor envergadura y alcance en el tiempo, es mucho mejor para su economía personal. Concurre también el factor académico-educativo, pues la formación universitaria se ha centrado en especializar al futuro profesional en el litigio y no en la negociación o conciliación, lo que conlleva a que se mire el conflicto primero con una solución legal y luego con reticencia a las soluciones que no sean procesales.

- La población no percibe el efectivo control por parte del Estado sobre la correcta operatividad de los centros de conciliación, por razones de presupuesto que es lo que constantemente se alega. En efecto, no hay centros clausurados o sancionados.

El empleo de la conciliación no debe ser considerada como una privatización de la justicia. Por el contrario, la manera de resolver diputas en el ámbito público del Poder Judicial constituye, paradójicamente, una privatización al estar "privados" del conocimiento de las reglas de juego, de las alternativas a nuestro alcance, del contacto con nuestros 
oponentes y con los jueces que deben resolver sobre nuestros diferendos y, muchas veces, de la confianza en nuestros abogados que padecen litigar en beneficio propio. La conciliación extrajudicial abre la posibilidad del contacto con el otro, es decir restablecer la relación interpersonal y las presencias corporales que permiten percibir todo lo que la relación social indirecta que imponen los tribunales atenúa y aún oculta.

En el foro, a pedido de los litigantes, y de la ciudadanía en general se ha formulado la modificación del sistema, teniendo en consideración a su vez el Informe Final del CERIAJUS que establecía la necesidad de derogar este requisito de obligatoriedad, considerando una limitación al acceso a la justicia, también la necesidad de implementar la expansión del procedimiento conciliatorio a nuevos temas. En ese sentido señalamos como propuestas:

- Mantener la conciliación pero como facultativa

- Proponer la disminución de su tarifa.

- Recomendar a los jueces para que consideren la asistencia o la inasistencia a las conciliaciones como partes de la conducta procesal.

- Promover el uso masivo de la conciliación.

Con la dación del Decreto Legislativo $\mathrm{N}^{\circ} 1070$ que modifica una serie de aspectos de la Ley No 26872-Ley de Conciliación Extrajudicial, y del Decreto Supremo No 014-2008JUS, Reglamento de la Ley de Conciliación Extrajudicial, el Gobierno ha hecho el intento de regularizar esta figura, pero dicho esfuerzo no ha sido buenamente recogido por la doctrina nacional $^{287}$, pues se viene criticando:

- La falta de definición entre la obligatoriedad y la no obligatoriedad de la institución conciliatoria en el ámbito nacional.

- El establecimiento de materias conciliables en numerus clausus

- La falta de sistematización con la Ley $\mathrm{N}^{\circ} 29227$, Ley que regula el procedimiento no contencioso de la separación convencional y divorcios ulterior en las Municipalidades y Notarías.

- El Acta de conciliación. ¿Título ejecutivo o título de ejecución?

- La posibilidad de que las partes puedan concurrir en la audiencia de conciliación extrajudicial mediante apoderados.

\subsubsection{Figuras verticales}

El tercero está supra-partes, domina a las partes y resuelve por ellas.

\section{a) Arbitraje}

Es la institución por la que las partes de una determinada relación jurídica someten voluntariamente a la decisión vinculante de uno o varios árbitros las cuestiones litigiosas que con ocasión de dicha resolución, se suscitan sobre derechos arbitrables.

Constituye un método de resolver extrajudicialmente controversias en virtud del cual las partes acuerdan mediante convenio arbitral someter la solución de determinados

${ }^{287}$ PARÉDEZ NEYRA, Iván y CORCUERA BÁRCENA, Úrsula, La necesidad de una evaluación jurídica sistematizada de la legislación conciliatoria: las nuevas reformas en la Ley y Reglamento de conciliación extrajudicial. En: Actualidad Jurídica, Tomo 183, Gaceta Jurídica Editores, Lima, febrero 2009. 
conflictos que hayan surgido o puedan surgir entre ellos respecto de una determinada relación jurídica, a la decisión vía laudo arbitral de uno o varios terceros denominados árbitros imparciales y ajenos a las partes y no integrado en un órgano judicial estatal. El arbitraje puede ser voluntario donde las partes acuerdan libremente someterse al arbitraje u obligatorio por el cual las partes están obligadas por el imperio de las normas legales en determinadas circunstancias.

Los principales Centros de Arbitraje que actualmente funciona en el país son:

- Cámara de Comercio de Lima

- Cámara Americana de Comercio ANCHAM PERU

- CEARCO PERU

- Colegio de Ingenieros del Perú CIP

- Colegio de Abogados de Lima CAL

Abordaremos ampliamente el arbitraje en el siguiente punto.

\section{El Proceso}

El Derecho Procesal como disciplina de la ciencia jurídica se ocupa del estudio del proceso. En cuanto a su noción tenemos que De Miguel y Alonso lo define como "una serie de actos que tienden a la resolución coactiva y práctica de los conflictos sociales mediante la actuación de la ley por medio de los órganos jurisdiccionales del Estado, garantizando un bien o un derecho protegido concretamente por la ley, o ejerciendo el poder punitivo del estado"288. Nos dice De La Plaza: "Convienen todos los tratadistas en que el proceso civil está integrado, de igual modo que el proceso biológico o químico (de processus: avanzar, progresar), por una serie de actos que tienden, fundamentalmente, a proteger un derecho" 289 En ese mismo orden de ideas, Morón Palomino considera que el proceso es "[un] conjunto de posiciones jurídicas activas y pasivas de las partes y el juzgador, en orden a la decisión jurisdiccional de la controversia jurídica suscitada por la pretensión del actor y la eventual resistencia del demandado" ${ }^{290}$.

Asimismo, Prieto-Castro define el proceso de la siguiente manera: "el proceso podemos conceptuarlo como el conjunto de actividades reguladas por el derecho procesal que realizan las partes y el tribunal, iniciado por una petición de otorgamiento de justicia a la jurisdicción, para alcanzar una sentencia u acto por el cual el Estado realiza su deber y derecho de defensa del orden jurídico objetivo privado, que implica la protección del derecho o del interés del justiciable que se en tal derecho objetivo"291. También Guasp, que al respecto dice lo siguiente: "es la institución jurídica que tiene por objeto la satisfacción

\footnotetext{
${ }^{288}$ De Miguel y Alonso, Carlos. Derecho Procesal Práctico, T. I, Barcelona, $11^{\mathrm{a}}$ edición, Editorial Bosch. 1967. p. 4

${ }^{289}$ DE LA PlAZA. Ob. cit., p. 7. Explicando un poco más su definición dice: "Para ello se requiere, puesto que se trata de una serie encadenada de actos que realizan, por un parte, los interesados en el conflicto, y por otra, los llamados a preparar su decisión o a pronunciarla con fuerza vinculante, arbitrar una fórmula cuyo valor intrínseco estará en directa relación con su eficacia para el logro del fin pretendido; y que habrá de exogitarse, como ha notado aquel tratadista, poniendo a contribución la experiencia, sin la cual difícilmente se conocerían los términos del conflicto, la sagacidad, para precisar el punto de equilibrio de los contrapuestos intereses, y la técnica, para hacerlo, según las directrices que presidan un sistema jurídico determinado" (DE LA PLAZA. Ob. cit., p. 8).

${ }^{290}$ Morón PAlOmino, Manuel. Derecho procesal civil, Madrid, 1983. p. 148.

${ }^{291}$ PRIETO-CASTRO Y FERRÁNDIZ, Leonardo. Derecho procesal civil. Madrid, 1989. 5ta. Edición. p. 33
} 
pública de pretensiones cuando estas pretensiones por las materias sobre que recaen afectan el ordenamiento jurídico privado" ${ }^{, 92}$. La definición propugnada por Ramos Méndez al referirse al proceso es como sigue: "El proceso es una sucesión ordenada de actos, según unas normas de procedimientos preestablecidos en función del juicio jurisdiccional",293.

En doctrina nacional citaremos a Monroy Gálvez, quien después de reconocer que el término proceso tiene muchas acepciones, lo limita al ámbito judicial, a diferencia del proceso legislativo y administrativo, y lo define de la siguiente forma: "El proceso judicial es el conjunto dialéctico de actos, ejecutados con sujeción a determinadas reglas más o menos rígidas, realizados durante el ejercicio de la función jurisdiccional del Estado, por distintos sujetos que se relacionan entre sí con intereses idénticos, diferentes o contradictorios, pero vinculados intrínsecamente por fines privados y públicos"294.

Como es fácil percatarse existen muchas definiciones sobre el proceso, lo que se ha intentado en primer lugar es citar algunos autores de los muchos que existen, con el objetivo de dar una visión panorámica del proceso, sin desmerecer a los no citados.

Quien pacientemente se pone a observar el modo en el cual se desarrolla el proceso judicial, puede darse cuenta que se trata de actividades humanas, actos jurídicos en general, distribuidos en el tiempo y en el espacio, siguiendo un cierto orden lógico, lo cual nos lleva a afirmar que "estas variadas actividades que componen el proceso, y que acaso siendo materialmente distintas y estando cronológicamente separadas la una de la otra, forman conceptualmente una serie continuada individualizada por la unidad del fin, constituyen actos jurídicos, y en cuanto a sus formas y sus efectos, están reguladas por la ley; y en ese sentido se habla en la doctrina y en la ley de actos procesales"295. Lo que sí es resaltante concebir en este momento al proceso como un conjunto de actos (llamados actos procesales por su regulación legal) y con ello vamos al aspecto dinámico del proceso, como un conjunto de actos tendientes a un fin.

También puede hablarse mucho de la finalidad del proceso. A fin de no ir por la tangente es menester referir aquí, que según el artículo III del Título Preliminar del Código Procesal Civil "el Juez deberá atender a que la finalidad concreta del proceso es resolver un conflicto de intereses o eliminar una incertidumbre, ambas con relevancia jurídica, haciendo efectivos los derechos sustanciales, y que su finalidad abstracta es lograra la paz social en justicia".

El proceso es pues una consecuencia necesaria de la eliminación por el Estado de las formas de auto tutela promoviendo la heterocomposición con la creación de la figura del juez y el proceso como método de debate legítimo para resolver los conflictos entre las personas.

292 GuASP, Jaime. Derecho Procesal. Instituto de Estudios Políticos", Madrid, Tercera edición corregida, 1968, p. 28.

${ }^{293}$ RAMOS MÉNDEZ, Francisco. Ob. cit., p. 13.

${ }^{294}$ Monroy Gálvez, Juan. Introducción al Proceso Civil. Temis, Santa Fe de Bogotá, 1996; pp. 112113. Igualmente define el maestro "Operativamente podemos definir el proceso judicial como el conjunto dialéctico de actos jurídicos procesales, realizados por los elementos activos de la relación jurídica procesal, con las finalidades de resolver el conflicto de intereses o acabar la incertidumbre jurídica y conseguir la paz social en justicia" (MonRoy GÉlveZ, Juan; La postulación del proceso en el Código Procesal Civil. En Thémis $\mathrm{N}^{\circ}$ $23 ;$ p. 33).

295 Calamandrei, Piero. Instituciones de Derecho Procesal Civil, Vol. II, traducción de la primera edición italiana por Santiago Sentís Melendo. Ediciones jurídicas Europa-América, Buenos Aires, 1962, pp. 318-319. 
Por eso el proceso civil germina sobre esta idea de que se inicia a solicitud de parte. Es un mecanismo por antonomasia a cargo de la jurisdicción (actividad llevada a cabo por el Poder Judicial) utilizado para resolver conflictos.

Como el objetivo del trabajo presente es una apuesta decidida por el arbitraje en adelante solo se hará referencia al arbitraje en detrimento del proceso jurisdiccional, no sin antes realizar un detalle de las principales diferencias entre ambos sistemas.

Siguiendo a Matheus López, se va a "determinar aquellos puntos de unión o distanciamiento que posee el proceso arbitral respecto de aquel jurisdiccional, a efectos de evidenciar -sin pretensiones de certeza apodíctica- las ventajas propias del arbitraje como real alternativa frente a la propuesta ofertada por la jurisdicción estática" ${ }^{\text {296 }}$.

\section{1. Ámbito de aplicación}

El proceso arbitral se realiza para la solución de pretensiones basadas en derechos disponibles, en tanto el proceso jurisdiccional se proyecta a la solución de pretensiones fundamentadas tanto en derechos disponibles o no.

\subsection{Métodos de resolución de conflictos}

Tanto el proceso arbitral como el jurisdiccional son clasificados en la categoría de mecanismos heterocompositivos verticales de resolución de conflictos, en razón de la existencia en ambos casos de un tercero que ubicado supra partes en una posición vertical resuelve el conflicto.

\subsection{Diferencia de origen}

El proceso arbitral posee un origen negocial, cuya base es el convenio arbitral. Y ello origina un proceso arbitral desarrollado por los denominados árbitros. En tanto el proceso judicial posee un origen jurisdiccional justificado en el desarrollo funcional de la potestad jurisdiccional del Estado.

\subsection{Naturaleza jurídica}

Según unánime clasificación en la doctrina, hablar sobre las teorías que explican la naturaleza jurídica del proceso, es referirse a dos corriente antagónicas, la privatista y la publicista, sin desmerecer por supuesto a otra teorías que pese a no haber alcanzado la importancia debida por la doctrina mayoritaria no dejan de ser importantes.

"En términos generales las teorías privatistas han tratado de explicar la naturaleza del proceso, ubicándolo dentro de las figuras conocidas del derecho privado, como el contrato o el cuasi contrato; las teorías publicistas, en cambio, han considerado que el

${ }^{296}$ MATHEUS LòPEZ, Carlos; Compulsa crítica entre el proceso jurisdiccional y Arbitral en el Sistema Jurídico peruano, en Revista de Derecho Internacional. Direito Internacional e do Mercosul. Nro. 4 Volumen 7. Buenos Aires, agosto.2003 
proceso constituye por sí solo una categoría especial dentro del derecho público, ya sea que se trate de una relación jurídica o bien de una serie de situaciones jurídicas" ${ }^{, 297}$.

Por su parte, en relación al proceso arbitral se han planteado como teoría explicativa: la contractualista (Guasp y otros), la jurisdiccionalista (Cordón, Reglero y otros), la ecléctica (Gaspar y otros) y la negocial procesal (Lorca).

\subsection{Común perspectiva garantista}

Tanto el proceso jurisdiccional como aquel arbitral viene concebidos como un sistema de garantías constitucionales compuestas principalmente por la audiencia bilateral, la igualdad y la contradicción; lo que supone luego que le son aplicables las garantías de un debido proceso.

\subsection{Composición subjetiva trilateral}

Tanto el proceso arbitral como el jurisdiccional importan -básicamente- una relación jurídica trilateral, compuestas por sujetos imparciales (órgano arbitral o jurisdiccional y sus órganos auxiliares respectivamente) y por sujetos parciales (parte activa o pasiva); pudiendo ser además los sujetos imparciales de orden singular (juez y árbitro único respectivamente) o colegiado (corte y tribunal arbitral respectivamente).

\subsection{Principio de contradicción}

En cualquier tipo de proceso las partes deben estar dispuestas como adversarios, en dos posiciones opuestas. Esas dos posiciones en colisión representan la estructura lógica del proceso, y están ineludiblemente avocadas a un procedimiento, en el transcurso del cual ha de tener lugar una auténtica dialéctica concretada en un cruce de alegaciones y, en definitiva, en una contradicción.

Suele confundirse las palabras contraposición y contradicción, que normalmente aparecen identificados. Ciertamente nos encontramos en presencia de dos vocablos semejantes, en cuanto tienen en común una misma raíz, lo que provoca que en el imaginario común compartan una idea de choque, encuentro, o colisión. "A saber, la contraposición entraña una divergencia entre las partes situadas en dualidad de posiciones porque hay intereses contrapuestos, lo que se materializa en el proceso en una litis o contienda"298; siendo así, llevada esta contraposición al proceso, es lógico que sus actuaciones se hagan contradictoriamente. Por su parte, "la contradicción hace referencia a la actuación de las mismas dentro del proceso, de forma que puedan rebatirse y cruzar sus respectivas alegaciones y pruebas, lo cual concierne al órgano articularlo"299.

\section{Tipologías utilizadas}

El proceso judicial posee una triple clasificación, sustentada en base a la clasificación de las pretensiones, distinguiéndose así tres tipos de proceso: proceso cognitivo, proceso de ejecución y proceso cautelar. En cambio, el proceso arbitral se clasifica siguiendo variados

297 Ovalle Favela, José. Teoría General del proceso. 3. a edición, Oxford University Press Harla México, México, 1996 p. 182

${ }^{298}$ CHOCRÓN GIRALDEZ, Ana María. Los Principios Procesales en el Arbitraje. Prólogo de Rosa Cobos Gavala; José María Bosch Editor; Barcelona, 2000; p. 71.

${ }^{299}$ Ibid. 
criterios, en, arbitraje de derecho y de conciencia, arbitraje institucional y ad hoc, arbitraje general y especial, arbitraje voluntario y forzoso.

\section{a. Carácter de la pretensión}

El proceso jurisdiccional se ocupa de la satisfacción de la pretensión justiciable (sea disponible o indisponible) en tanto el proceso arbitral se ocupa de la pretensión arbitrable (solo disponible).

\section{b. Sobre la capacidad y legitimación}

Tanto en el proceso arbitral como el jurisdiccional, podemos apreciar en cada caso, la necesidad de que las partes o los sujetos parciales cuenten con capacidad procesal, entendida como la aptitud de realizar eficazmente actos y/o negocios jurídicos procesales, sea a nombre propio o por cuenta ajena, porque se posee el libre ejercicio de los derechos que en el proceso se hacen valer.

Por su parte en el proceso judicial se requiere contar con legitimidad para obrar que no es otra cosa que la afirmación de titularidad respecto de la pretensión justiciable. En tanto en el proceso arbitral, la legitimidad viene determinada sobre la base de la suscripción del convenio arbitral.

\section{c. Tratamiento de la pendencia y la litispendencia}

Debe conocerse desde el momento que se inicia un proceso. Por ello debemos saber desde cuando un proceso se encuentra pendiente. Debe tenerse cuidado al decir que un proceso se encuentra pendiente, porque no es lo mismo que identificarlo con el concepto de litispendencia. Pendencia es un estado que se produce en un lapso de tiempo comprendido entre el inicio del proceso jurisdiccional y su final. Litispendencia es el conjunto de efectos procesales, legítimamente previstos a favor de una o ambas partes, que se manifiestan durante la pendencia de un proceso con el objetivo de garantizar la eficacia de la futura definición judicial del derecho desde la perspectiva de la duración de dicho proceso, evitando que esta duración perjudique al derecho a la tutela judicial efectiva de los litigantes. Entonces debemos avocarnos solo al tema de la pendencia y especialmente a conocer desde cuando un proceso se encuentra pendiente. Al respecto se postulan cuatro teorías:

a).- Teoría de la presentación de la demanda.

b).- Teoría de la admisión de la demanda.

c).- Teoría del emplazamiento efectivo con la demanda.

d).- Teoría de la contestación de la demanda.

Es obvio que tanto la doctrina como cada legislación en particular, escogerán tal o cual teoría. Por ejemplo, en el Perú, una interpretación sistemática de nuestro Código Procesal nos llevará a decidir por la tercera de ellas, pero en España, por otro lado, es expresa la adhesión a la primera teoría (la de presentación de la demanda). En conclusión, en el Perú, el proceso se inicia con el emplazamiento efectivo de la demanda al demandado

En tanto, en el proceso arbitral, debe distinguirse el supuesto de órgano arbitral singular de aquel colegiado, pues en el primero se produce la pendencia, origen de la 
litispendencia arbitral, cuando aquel notifique a las partes su aceptación, mientras que en el segundo caso, se produce aquella con la notificación de la instalación del tribunal arbitral.

\section{d. Costes}

En el proceso judicial los costes, conformados por las costas y costos, vienen dados por las tasas judiciales, honorarios de órganos de auxilio judicial y el del abogado de la parte vencedora, así como otros gastos procesales. En tanto sucede que los costes de un proceso arbitral vienen conformados por los honorarios de los árbitros, de los abogados y del secretario arbitral, así como los gastos de protocolización del laudo y eventualmente la retribución a la institución arbitral. Además cabe poner en relieve que en el proceso jurisdiccional rige la regla de que los costes los asume el vencido, mientras que en el proceso arbitral la regla general será que cada parte asume sus propios costes, salvo pacto distinto en el convenio arbitral.

\section{e. Auxilio}

En el proceso judicial existe la institución denominada auxilio judicial, llamada antes beneficio de pobreza, empero en el proceso arbitral no se encuentra una norma que habilite tal beneficio.

\section{f. Intervención de terceros}

El fenómeno de la intervención sucede cuando en un proceso ya iniciado, ingresa un sujeto extraño, distinto a las partes originarias y por ello un tercero; así intervención procesal no es más que el ingreso de un tercero en una causa llevada entre otras personas, para defender un interés propio. Los tipos de intervención se dividen mayormente entre intervención voluntaria y forzosa. Sucede tanto en el proceso jurisdiccional como en el proceso arbitral.

\section{g. Principio de dualidad}

Más que un principio es una necesidad lógica de la estructura del proceso. Es consustancial a todo proceso. Para que pueda constituirse válidamente un proceso jurisdiccional es necesaria la presencia de dos partes.

No es exactamente que existan dos partes. Es una dualidad de posiciones en la que cada parte asume una posición distinta de la otra y viceversa.

Ya indicamos que cada una de estas partes asume una posición, pero pueden llegar a suceder algunos acontecimientos de carácter subjetivo dual, que consiste en que cada una de esas posiciones puede estar ocupada por más de una parte; en ese caso estaríamos ante una pluralidad de partes en dualidad de posiciones. El principio de dualidad de posiciones queda a salvo, no se verá afectado si dentro de esas posiciones hay una pluralidad de partes que se llama técnicamente litisconsorcio. De tal forma, podrán presentarse en el proceso arbitral como en el jurisdiccional supuestos tanto de litisconsorcio necesario, como también de litisconsorcio voluntario y cuasi necesario. 


\section{h. Determinación y posicionamiento de las partes}

Se considera que por determinación de la parte debe entenderse como señalar o fijar que un determinado sujeto, y no otro, pertenece a un determinado proceso o integra una relación jurídica procesal específica. Dicha determinación "reviste especial importancia porque, por un lado, permite identificar los sujetos de la relación jurídico procesal, de tal suerte que los sujetos adoptan sus respectivas posiciones no pudiendo "ni unirse a sí mismas ni al adversario como coadyuvantes, ni ser testigos"; y, por otro lado, permite determinar las causales de impedimento y recusación del Juez a cargo del asunto (arts. 305 y 307 del CPC); permite definir si existe litispendencia (arts. 446 inc. 7 y 452 del CPC) y cosa juzgada (art. 446 inc. 8 y 452 del CPC); la declaración de parte (arts. 213 y ss. del CPC) y la responsabilidad por el pago de costas y costos (arts. 410 y ss. del CPC) "300. La determinación y posicionamiento de las posiciones de parte en el proceso jurisdiccional se produce en la demanda. De modo distinto, le arbitraje no se inicia por demanda sino más bien con la notificación del órgano arbitral, razón por la cual la tipicidad de cada posición parcial depende de la actividad del árbitro que inicia el proceso.

\section{i. Nacionalidad de los sujetos procesales}

Las partes en ambos procesos, tanto arbitral como jurisdiccional, podrán ser tanto nacionales como extranjeras, siempre que cuenten con capacidad procesal; afirmar lo contrario sería un acto discriminatorio contra ciudadanos no nacidos en territorio nacional. Sin embrago, mientras que en el proceso jurisdiccional el juez debe ser peruano, en el proceso arbitral, el árbitro pude ser tanto peruano como extranjero.

\section{j. Designación del órgano imparcial}

El Juez del proceso jurisdiccional es parte de una estructura orgánica que se encarga de la potestad jurisdiccional del Estado y como tal viene predeterminado e impuesto orgánicamente; mientras que el árbitro es elegido por las partes negocialmente.

\section{k. Capacidad del órgano imparcial}

Tanto en el proceso jurisdiccional como el proceso arbitral existe la exigencia de que el sujeto imparcial decidor cuente con ajeneidad y compatibilidad respecto del proceso, estableciéndose normativamente los supuestos en que no se cuente con tal capacidad, tales como aquellos de impedimento y recusación del juez y los de incompatibilidad y recusación del árbitro.

\section{l. Profesionalidad del órgano imparcial}

Comúnmente se alega para el proceso jurisdiccional la baja especialización del juez, siendo más justo decir la única especialización del juez, toda vez que el juez necesariamente debe ser abogado, tenga alta o baja especialización. En cambio en el proceso arbitral existe la figura del árbitro escabino, el cual cuenta con un conocimiento especializado o profesional, en una materia concreta.

${ }^{300}$ MORALES GODO, Juan. “Apuntes sobre la noción de parte en el proceso civil”. En: Revista Peruana de Derecho Procesal. Tomo III, Lima. p. 199. 


\section{m. Órgano imparcial colegiado}

En el proceso jurisdiccional el órgano imparcial puede ser único o colegiado. Los órganos colegiados del Poder Judicial, como las salas superiores y supremas, cuentan con una composición legal predeterminada de tres y cinco miembros, respectivamente. En el proceso arbitral la única exigencia en cuanto al número del colegiado es que la cantidad de miembros del colegiado sea impar.

\section{n. Incorporación al órgano imparcial}

El juez del proceso jurisdiccional se encuentra obligado a asumir la causa sometida a él cuando sea competente, pudiendo solo apartarse de su conocimiento en casos puntuales de impedimento y recusación. Mientras que en el proceso arbitral se requiere la aceptación del árbitro a efectos asuma los deberes y obligaciones propias del arbitraje, dependiendo en último caso de su voluntad el conocimiento de la causa arbitral

\section{o. Otros sujetos imparciales}

Presentes en el proceso jurisdiccional se encuentran al lado del juez los auxiliares de la administración de justicia que son parte de la estructura orgánica propia de la jurisdicción. Más en el proceso arbitral un auxiliar como el secretario arbitral es contingente, pudiendo existir como tal o no, presentándose la figura del árbitro- secretario.

\section{p. Responsabilidad}

El tratamiento de la responsabilidad civil del juez se caracteriza por ser una pretensión típica con un procedimiento civil ya previamente fijado en vía de proceso abreviado, en cuanto la responsabilidad civil del árbitro no posee un tratamiento específico, debiendo ser conducida a las normas generales aplicables de la responsabilidad profesional.

\section{q. Retribución económica del órgano imparcial}

El Juez es un servidor público de un estamento del Estado, y como tal recibe una retribución consistente en un sueldo fijo mensual por su trabajo desarrollado; en tanto el árbitro recibe por su labor un honorario por cada proceso arbitral, determinado generalmente sobre la base de un baremo.

\section{r. Intervención recíproca}

Tanto el proceso jurisdiccional como el proceso arbitral tienen recíprocas intervenciones uno en el otro; así el proceso judicial interviene en el proceso arbitral mediante instituciones tales como en la complementación de la actividad probatoria, la ejecución de una medida cautelar, la apelación, la ejecución del laudo nacional, el reconocimiento y ejecución del laudo extranjero. Por su parte, el proceso arbitral interviene en el jurisdiccional mediante la llamada excepción de convenio arbitral y la cosa juzgada. 


\section{s. Inactividad de las partes}

El abandono en el concepto procesal es la paralización o inactividad en la tramitación del juicio, durante el término de ley, que en nuestro caso es cuatro meses. La institución del abandono tiene el mismo fundamento que el de la prescripción, de la que se diferencia en que esta es adquisitiva o extintiva, y aquel solamente es extintivo. En que la prescripción extintiva se fulmina la acción y el abandono pro su parte aniquila la instancia o el recurso pero deja viva la acción. Al abandono del proceso también se le denomina abandono de la instancia, perención o caducidad de la instancia.

Mientras que en el proceso arbitral tal inactividad no supone la conclusión del proceso ni impide que el órgano arbitral pronuncie el laudo sobre la base de lo actuado.

\section{t. Plazos procesales}

Generalmente el régimen de plazos en el proceso jurisdiccional es imperativo y su incumplimiento puede derivar en supuestos de nulidad, el plazo arbitral posee una significación negocial.

\section{u. Lugar del procedimiento}

En el proceso jurisdiccional las reglas sobre el lugar en el cual va a desarrollarse el proceso se fijan en base a las reglas de competencia territorial, pudiéndose dar como excepción la prórroga convencional de esta. En tanto en el arbitraje el lugar de realización del proceso se fija de forma convencional.

\section{v. Resoluciones}

Las resoluciones de los proceso jurisdiccionales son: $i$ ) Decretos ${ }^{301}$ o resoluciones de mero trámite; ii) Autos $^{302}$, que son resoluciones en las cuales debe haber fundamentación, donde se motiva la decisión pero no se falla sobre la pretensión, y ocasionalmente pueden poner fin al proceso; iii) Sentencia ${ }^{303}$ que es la resolución que pone fin a un proceso y se pronuncia sobre la pretensión estimándola o no.

Por otro lado, las resoluciones arbitrales son solo dos: laudo arbitral y resoluciones distintas al laudo.

${ }^{301}$ Código Procesal Civil, Artículo 121.- Decretos, autos y sentencias.- Mediante los decretos se impulsa el desarrollo del proceso, disponiendo actos procesales de simple trámite.

${ }^{302}$ Código Procesal Civil, Artículo 121.- Decretos, autos y sentencias.- (...)

Mediante los autos el Juez resuelve la admisibilidad o el rechazo de la demanda o de la reconvención, el saneamiento, interrupción, conclusión y las formas de conclusión especial del proceso; el concesorio o denegatorio de los medios impugnatorios, la admisión, improcedencia o modificación de medidas cautelares y las demás decisiones que requieran motivación para su pronunciamiento.

${ }^{303}$ Código Procesal Civil. Artículo 121.- Decretos, autos y sentencias.- (..)Mediante la sentencia el Juez pone fin a la instancia o al proceso en definitiva, pronunciándose en decisión expresa, precisa y motivada sobre la cuestión controvertida declarando el derecho de las partes, o excepcionalmente sobre la validez de la relación procesal. 


\section{w. Probática}

En el proceso jurisdiccional rige el principio de formalidad probática, en tanto en el proceso arbitral rige el principio de libertad formal, lo que quiere decir que en el primero mientras que el juez se encuentra obligado a utilizar todos los medios de prueba administrados- a efectos de su decisión, el árbitro puede prescindir motivadamente de un medio de prueba si lo considera adecuado. De otro lado, en el proceso jurisdiccional rige cual sistema de valoración de valoración de la prueba el sistema de apreciación conjunta, mientras que en el proceso arbitral se utiliza el sistema de libre valoración.

\section{y. Obligatoriedad del fallo}

Se tiene que mientras la sentencia deviene en obligatoria por un sustento jurisdiccional, porque así se respeta la potestad jurisdiccional del Estado, el laudo arbitral posee una base negocial, dado que este se cumple y obliga a las partes porque negocialmente así lo desearon las partes.

\section{Motivación del fallo}

Sucede que en el proceso jurisdiccional la motivación siempre es jurídica, en tanto que en el proceso arbitral puede también serlo como no. Esta última situación se presenta en el arbitraje de conciencia en el cual la motivación es extra jurídica.

\section{Corrección, integración y aclaración}

Cabe indicar que tanto en el proceso jurisdiccional como arbitral se reconocen los mal llamados recursos de corrección, integración y aclaración de la sentencia y del laudo arbitral, respectivamente.

\section{Firmeza y cosa juzgada}

La firmeza es un elemento necesario de la preclusión procesal, pues dentro de un proceso debe haber momentos que se van cerrando. Los actos procesales deben tener un plazo para ser cumplidos, y debe llegarse a un momento en el cual transcurrido el plazo, ya no se puede cumplir un acto procesal válidamente entonces la firmeza no es sino un elemento necesario de la preclusión.

La cosa juzgada es el efecto de inatacabilidad o cobertura contra ataques que esta genera hacia fuera del proceso, por eso se dice es extra procesal, es decir con relación a los demás procesos. Los efectos de la cosa juzgada aquí pues no tienen carácter interno, sino externo, no se reflejan en el proceso en que se produce la cosa juzgada, sino en otro posterior. Es este lo que en verdad debe entenderse por cosa juzgada, si advertimos es innecesario denominarla "material "o "sustancial" pues asumiendo que la cosa juzgada es igual a firmeza, solo existe una noción única de cosa juzgada aunque la doctrina la sigue llamando material.

Tanto en el proceso jurisdiccional como en el arbitral (dada la presencia en ambos del principio de preclusión) podemos advertir tanto la firmeza -mal llamada cosa juzgada formalcomo también de la cosa juzgada estricta o material. 


\section{z. Medios de impugnación ordinarios}

Se denomina medio de impugnación ordinario aquel que cuestiona, ataca o discute una resolución que aún no ha adquirido autoridad de cosa juzgada, siendo estos en el proceso jurisdiccional, la reposición, la apelación, la casación y la queja. En tanto, en el proceso arbitral solo existe la reposición, apelación (ante instancia judicial o arbitral) y anulación.

\section{Medio de impugnación extraordinario}

Se conoce como medio de impugnación extraordinario aquel que ataca una resolución que ya ha adquirido autoridad de cosa juzgada, siendo por antonomasia la mal llamada "nulidad de la cosa juzgada fraudulenta" aquel propio del proceso jurisdiccional. Sin embargo, no encontramos expresamente regulado un medio de este tipo para el proceso arbitral.

\section{Proceso cautelar}

No es extraño ver en el proceso jurisdiccional que el juez sea quien adopta y ejecuta la medida cautelar, lo cual no se presenta en el proceso arbitral, donde si bien la adopción de la medida viene decretada por el árbitro, la ejecución de aquella es llevada a cabo por el juez.

\section{Ejecución forzosa del fallo}

En el proceso jurisdiccional la sentencia judicial o la resolución judicial firme adquieren la calidad de título de ejecución, pudiendo ser ejecutadas a través del proceso de ejecución de resoluciones judiciales. En tanto, en el proceso arbitral solo el laudo arbitral firme adquiere la calidad de título de ejecución, más no las resoluciones arbitrales firmes, razón por la cual estas últimas no podrán acceder al proceso de ejecución de resoluciones judiciales.

\section{Reconocimiento y ejecución del fallo extranjero}

Cabe señalar que indistintamente un laudo arbitral como la sentencia judicial extranjera, puede ser objeto de reconocimiento y posterior ejecución en nuestro país, de conformidad a los tratados vigentes.

\section{Conclusiones}

\section{(Ventajas de los mecanismos alternativos de resolución de conflictos respecto al proceso judicial)}

1. La economía procesal no solo implica economía de esfuerzo que significa concentrar en pocas audiencias numeroso actos que implica un proceso civil, sino además la economía de costos, al ser absolutamente reducido el nivel de inversión para acceder a los medios alternativos, o por los gastos y honorarios profesionales que eventualmente signifiquen.

2. La velocidad de resolución del conflicto entre ambos es absolutamente incontrastable. 
3. La informalidad y la simplicidad del trámite se diferencia con el apego a formas incluso solemnes que origina un proceso jurisdiccional complejo, por lo que se piensa que el proceso judicial es muy técnico o que deba ser utilizado por poderosos y abogados.

4. La ausencia de una justicia verdadera de menor cuantía en el proceso jurisdiccional incentiva más el empleo de los medios alternativos.

5. Nada escapa que a través de estos mecanismos se descongestiona la actividad tribunalicia liberando a los jueces de tareas que otros muchos pueden realizar con mayor seguridad y eficacia. 


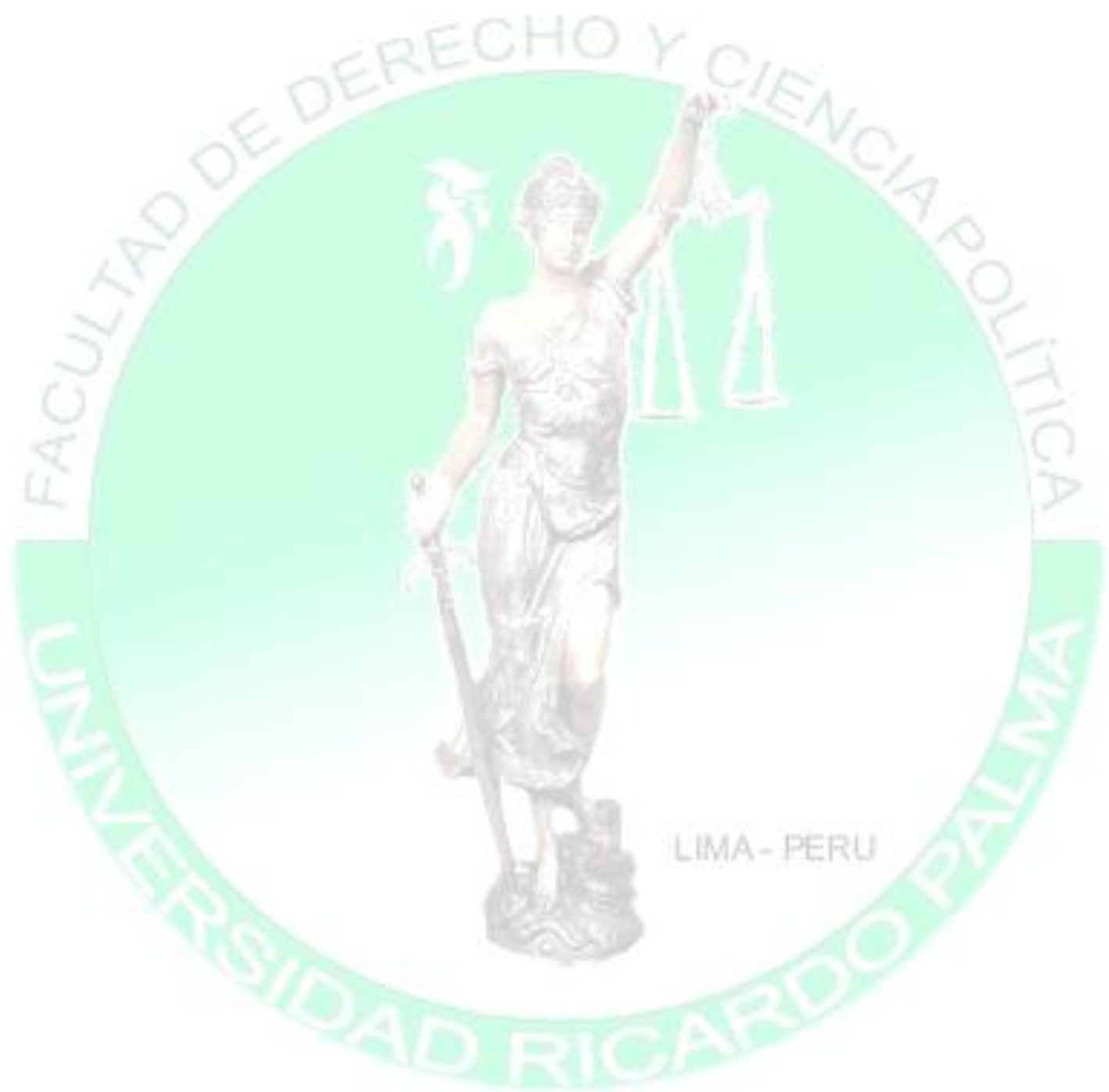

